\title{
Enthalpy of Combustion of Microcrystalline Cellulose
}

\author{
J.C. Colbert*, He Xiheng†, and D.R. Kirklin* \\ National Bureau of Standards, Washington, DC \\ 20234
}

August 14, 1981

\begin{abstract}
A test substance with characteristics and properties similar to those of cellulose-based solid waste products is needed to calibrate calorimeters and combustors which will be routinely burning these materials to determine their calorific values precisely for use in commerce. Microcrystalline cellulose was found to be a good calibrant for this purpose. The enthalpy of combustion of microcrystalline cellulose $\Delta \mathrm{H}_{c}^{\circ}$ at $\left(25{ }^{\circ} \mathrm{C}\right)$, and its estimated uncertainty, was determined to be $-2812.401 \pm 1.725 \mathrm{~kJ} / \mathrm{mol}$ based upon the sample mass.

A calculated heat of wetting correction of $1.514 \mathrm{~kJ} / \mathrm{mol}$ was applied to the combustion data.
\end{abstract}

Keywords: alternative fuel, bomb calorimetry, cellulose, enthalpy of combustion, refuse-derived-fuel, test substance.

\section{Introduction}

The enthalpies of combustion of heterogeneous feedstocks such as refuse-derived-fuel (RDF) and wood wastes, are important thermochemical data because of the potential application of these materials in commerce as supplemental or alternative fuels. When determining the enthalpy of combustion of RDF in a conventional bomb calorimeter or a newly designed multi-kilogram flow calorimeter, it is desirable to have a "test substance"'[1]" which can be used for their calibration which is as close to RDF in character as possible. This test substance will permit the intercomparison of the thermochemical results of different investigators in the new field of fuels from cellulose-based solid wastes and will essentially serve to control the chemical part of the investigation. Since there is a large fraction of cellulosic materials (i.e., paper products) in municipal solid waste (MSW), we decided to investigate the possibility of using a pure cellulose as a test substance. Cellulose not only has a close compositional relationship to the major components of MSW, but also possesses a similar kinship to wood species, wood wastes from the manufacture of paper, bagasse from the sugar refining industry, agricultural wastes, and some forms of peat. These materials have a potential as supplemental or alternative fuels just like RDF.

† Guest worker from July 1980-February 1981, Chemistry Laboratory, National Institute of Metrology, P.O. Box 2112, Peking, People's Republic of China.

- Center for Chemical Physics, Chemical Thermodynamics Division

'Numbers in brackets indicate literature references at the end of this paper.
A search was carried out to find a suitable cellulosic test substance. We needed a cellulose which was high in purity, homogeneous, inexpensive, easy to pelletize, and one which could be obtained in large quantities. Avicel, ${ }^{2}$ a readily available commercial cellulose, was chosen because it possesses most of the requirements for use as a calibrant in a bomb calorimeter. This cellulose is very homogeneous, 99.81 percent pure, and presses into a pellet very easily.

Calibration of the oxygen bomb calorimeter was performed using SRM benzoic acid, standard sample, 39i, which is the accepted primary standard substance for calibrating bomb calorimeters. Comparative calorimetric measurements were conducted on the cellulose sample. These measurements for benzoic acid and cellulose, along with the heat of wetting correction for cellulose, are presented in this paper.

\section{Experimental}

\subsection{Sample Characterization}

Avicel, $\mathrm{pH}-101$, lot $1018-152$, is a microcrystalline cellulose, which is an acid hydrolyzed derivative of a dissolving grade of wood pulp. It has an average particle size of 50 micrometers and a pH of 5.5 to 7 .

The sample was not subjected to any further purification but these additional analyses were made to further

\footnotetext{
${ }^{2}$ The commercial sources cited in this paper are included to adequately describe the experimental procedure. Such identification does not imply recommendation or endorsement by the National Bureau of Standards.
} 
characterize the cellulose. The percent moisture of seven cellulose samples was $4.910 \pm 0.060$ (sd.) at a relative humidity of 36 percent, as determined by drying in a 105 ${ }^{\circ} \mathrm{C}$ oven until a constant weight was reached.

The water soluble impurities of fluoride, chloride, nitrate, and sulfate were analyzed for by the method of ionchromatography. ${ }^{3}$ Two cellulose samples of different masses, $0.51 \mathrm{~g}$ and $1.62 \mathrm{~g}$ were diluted in a solution containing the buffer: $0.003 \mathrm{M} \mathrm{NaHCO} / 0.0018 \mathrm{M} \mathrm{Na} \mathrm{NO}_{3}$. The diluted sample was mixed, allowed to settle, and filtered through a 0.2 micrometer syringe filter. The average concentration of water soluble impurities for the two samples was $62.46 \mathrm{ppm}$. This level of anions is negligible when looking at the overall sample purity.

The amount of ash was found to be negligible when determined according to the American Society for Testing and Materials (ASTM) Standard Test Method D-3174-73 for Coal and Coke. The samples were fired for two hours in a furnace operating at $575-600^{\circ} \mathrm{C}$.

The purity of the Avicel was determined in duplicate $\mathrm{CO}_{2}$ analyses of the bomb combustion products. The gaseous products of combustion were released from the bomb and passed through absorption tubes containing Ascarite and magenesium perchlorate for removal of $\mathrm{CO}_{2}$ and $\mathrm{H}_{2} \mathrm{O}$, respectively, and phosphorus pentoxide [2] to prevent the back-flow of moist room air into the absorption system. The amount of $\mathrm{CO}_{2}$ was then determined gravimetrically. The purity of the cellulose was found to be $99.809 \pm 0.103$ (sd.) percent.

\subsection{Description of Calorimeter}

The combustion measurements were made in an isoperibol oxygen bomb calorimeter. This is an isothermaljacket calorimeter with the calorimeter reaction vessel submerged in a water bath at $301 \mathrm{~K}$ and controlled to $\pm 0.003 \mathrm{~K}$. This prevents any thermal leakage between the laboratory environment and calorimeter. The heat generated when a measured amount of sample is burned is compared to the heat evolved when a measured amount of standard substance is burned in the same calorimetric system. Benzoic acid, the primary calibrant, is burned and produces a three degree temperature rise in the calorimeter. The energy equivalent of the calorimeter is determined from the amount of energy produced by the benzoic acid and divided by the temperature rise. The temperature rise is corrected for the stirring energy produced in the stirred water of the calorimeter vessel and any thermal leakage between the environment and calorimeter.

In a cellulose experiment, the corrected temperature rise

'The analyses were performed by the Inorganic Analytical Research Division of the National Bureau of Standards. is multiplied by the energy equivalent of the calorimeter. This calulation gives the total energy produced in a cellulose combustion experiment. This total energy is finally corrected for any side reactions, or thermal corrections, and is divided by the mass of the cellulose sample to produce the internal energy of combustion at constant volume, $\Delta U_{c}^{\circ}$. Conversion to the enthalpy of combustion at constant pressure, $\Delta H_{c}^{\circ}$, carried out by applying a correction term for pressure-volume expansion $(\triangle \mathrm{nRT})$. The $\triangle n R T$ term for this reaction is 0 , therefore $\Delta U_{c}^{\circ}=\Delta H_{c}^{\circ}$.

All of the cellulose samples for combustion are pressed into pellets under an approximate force of $44.4 \mathrm{kN}$. A sample weight of $2.3 \mathrm{~g}$ was pre-determined in a trail experiment as the necessary amount of sample required to produce a three degree temperature rise.

\subsection{Sample Preparation}

A dried sample weight is necessary for the combustion experiments. Since cellulose is very hygroscopic, this was very difficult. The samples were placed into pre-weighed ground glass neck weighing bottles, dried at $105{ }^{\circ} \mathrm{C}$ until a constant weight of $\pm 0.3 \mathrm{mg}$ was obtained, and stored in a desiccator over $\mathrm{P}_{2} \mathrm{O}_{5}$ until ready for testing.

\subsection{Example of Calorimetric Procedure}

A dried pellet was transferred from the weighing bottle to a preweighed platinum crucible. The empty weighing bottle was again weighed to account for any cellulose remaining in the bottle. The platinum crucible with pellet was placed on the crucible support of the bomb head. The fuse leads had been previously connected with a $2 \mathrm{~cm}$ length of $0.075 \mathrm{~mm}$ platinum wire which is placed in contact with the top of the pellet. Normally, $1 \mathrm{ml}$ of water is added to the bottom of the bomb to provide a saturated atmosphere and ensure that water formed as a combustion product is present in the liquid state. For this series of cellulose combustions, $0.2 \mathrm{ml}$ of water was added directly to the pellet in the crucible and $0.8 \mathrm{ml}$ added to the bottom of the bomb. The sample was wetted before burning because it was found in the previous study by Jessup and Prosen $[3]^{4}$ that a more complete combustion results with a wetted sample rather than a dry one.

The sealed bomb is charged with $3.10 \mathrm{MPa}(30.62 \mathrm{~atm})$ of high purity oxygen and placed on the bench for approximately 1 hour for the sample to equilibrate with the moist environment inside the bomb. The calorimeter vessel is filled with a known amount of water, the bomb is lowered into the vessel, and the covered calorimeter is submerged in the constant temperature water bath. The rate of tempera-

- In a private consultation with EJ. Prosen, who had done a similar study in 1950 , we were advised to wet the cellulose sample before placing it in the bomb. 
ture rise is measured during the period before the sample is ignited, during the reaction period immediately after the sample is ignited, (main reaction period), and during the period after the reaction is completed. The difference between the temperature at which the final drift rate begins, and the temperature at which the sample is ignited, gives the observed temperature rise. The slope of the fore- and after-periods allows one to calculate that portion of the temperature rise due to stirring energy and thermal leakage [4].

\section{Results and Discussion}

\subsection{Correction for Heat of Wetting of Cellulose}

Since the samples were wet when they were ignited in the bomb, the heat produced in the combustion reaction is lower than for a dry sample. This amount of heat is equal to the heat of wetting and has to be corrected for in the calculation for the enthalpy of combustion. These heat of wetting determinations were not experimentally performed in the laboratory because of time constraints, and after searching the literature, it was felt an adequate amount of data already existed so that a calculated correction could be made.

The literature search extended back to 1948 or to about the time period when Jessup and Prosen's calorimetric work on cellulose was carried out at NBS [3]. Table I gives a summary of the heat of wetting data on cellulose in the literature. Rees' result of 46.02 [12] was in the same range as the other data listed, but his heat of wetting data also included the actual data points at different moisture contents of the sample. It was also presented in such a way as to easily select which sample was the closest counterpart to our Avicel sample.

TABLE I. Published Data on $\Delta H$ Wetting of Cellulose

\begin{tabular}{l|c|l|l}
\hline \multicolumn{1}{c|}{ Researcher } & Type of cellulose & $\mathrm{T}{ }^{\circ} \mathrm{C}$ & $\begin{array}{c}\Delta \mathrm{H} \text { wet. } \\
\text { cal/g(J/g) }\end{array}$ \\
\hline Jessup, et al, 1950[3] & wood pulp & 30 & $14.1(58.95)$ \\
Jessup, et al, 1950[3] & cotton linters & 30 & $11.2(46.80)$ \\
Wahba, et al, 1952[5] & standard cellulose & 20 & $11.0(46.02)$ \\
Wahba, 1948[6] & raw cotton & 30 & $12.2(51.04)$ \\
Wahba, 1950[7] & standard cellulose & 30 & $10.72(44.85)$ \\
Wahba, 1959[8] & stabilized cellulose & 30 & $10.52(44.02)$ \\
Wahba, 1959[8] & unstabilized cellulose & 29.8 & $10.70(44.77)$ \\
Wahba, 1975[9] & stabilized cellulose & 15 & $11.48(48.03)$ \\
Argue, et al, 1935[10] & standard cellulose & - & $10.16(42.51)$ \\
Morrison, et al, 1959[11] & cotton cellulose & - & $12.33(51.59)$ \\
Rees 1948[12] & American cotton & 25 & $11.0(46.02)$ \\
\hline
\end{tabular}

allulose treated by repeated wetting and drying.

${ }^{b}$ Heated samples in air at $100^{\circ} \mathrm{C}$.

c Dried at room temperature.
Using his data for cotton we were able to fit it to a least squares program and generate a polynomial expression for the data. Using that curve we selected hypothetical moisture contents for the cellulose sample that gave a calculated heat of wetting that reached a minimum value. The equation which was generated is given below:

$$
Y=10.8719-2.16135 X+0.13516 X^{2}
$$

where $Y$ is the resulting calculated heat of wetting correction, $2.23134 \mathrm{cal} / \mathrm{g}(9.33592 \mathrm{~J} / \mathrm{g})$, and where $X$ is the mass fraction of the moisture present in the cellulose sample before absorption begins. The value for the heat of wetting of cellulose was multiplied by the mass of cellulose burned in each experiment and the resulting numbers used as the correction for each heat of combustion measurement.

\subsection{Bomb Calorimetric Measurements}

Standard Reference Material, benzoic acid (SRM 39i), was used as the calibrant for the calibration experiments and has an energy of combustion of $26434 \pm 3 \mathrm{~J} / \mathrm{g}$ at $25^{\circ} \mathrm{C}$ and standard bomb conditions. The average energy equivalent of the calorimeter (Esi) was determined from nine benzoic acid combustions and was found to be $14347.75 \pm$ $0.82 \mathrm{~J} / \mathrm{K}(\mathrm{sdm})$ at $301 \mathrm{~K}$. Table II contains the detailed presentation of the nine calibration experiments, numbered from 1000-1013. The headings, in the order in which they appear in the table, are defined as follows:

Expt. No., the number of the experiment, which can easily be traced back to our records.

$\Delta U_{c}^{\circ}\left(28^{\circ} \mathrm{C}\right)$, the internal energy evolved by the combustion of benzoic acid at the selected final temperature in $\mathrm{J} / \mathrm{g}$.

$m-B A(v a c)$, the mass of the benzoic acid sample, in $\mathrm{g}$, reduced to mass in vacuum.

$q-B A$, the energy evolved by the combustion of benzoic acid, in $\mathrm{J}$.

$q$-ign, the electrical energy added to the system to ignite the sample, in $\mathrm{J}$.

$q-\mathrm{HNO}_{3}$, the energy evolved by the formation of nitric acid in the combustion process, in $\mathrm{J}$. (usually due to nitrogen impurities in the oxygen).

$q-\not C C$, The Washburn Correction $[13,14,15]$ applied to correct the combustion data from bomb conditions to conditions in which the reactants and products are in their pure standard states at one atmosphere pressure, in J.

$Q$-total, the total energy delivered to the calorimeter after corrections for ignition energy, formation of nitric acid, and Washburn correction, in J.

$\Delta T$-corr, the observed temperature rise of the calorimeter corrected for stirring energy and thermal leakage, in $\mathrm{K}$.

$E$-cal, the energy equivalent of the actual calorimeter system at the final temperature, $\left(28^{\circ} \mathrm{C}\right)$ in $\mathrm{J} / \mathrm{K}$. 
Table II. Benzoic Acid Calibration Results.

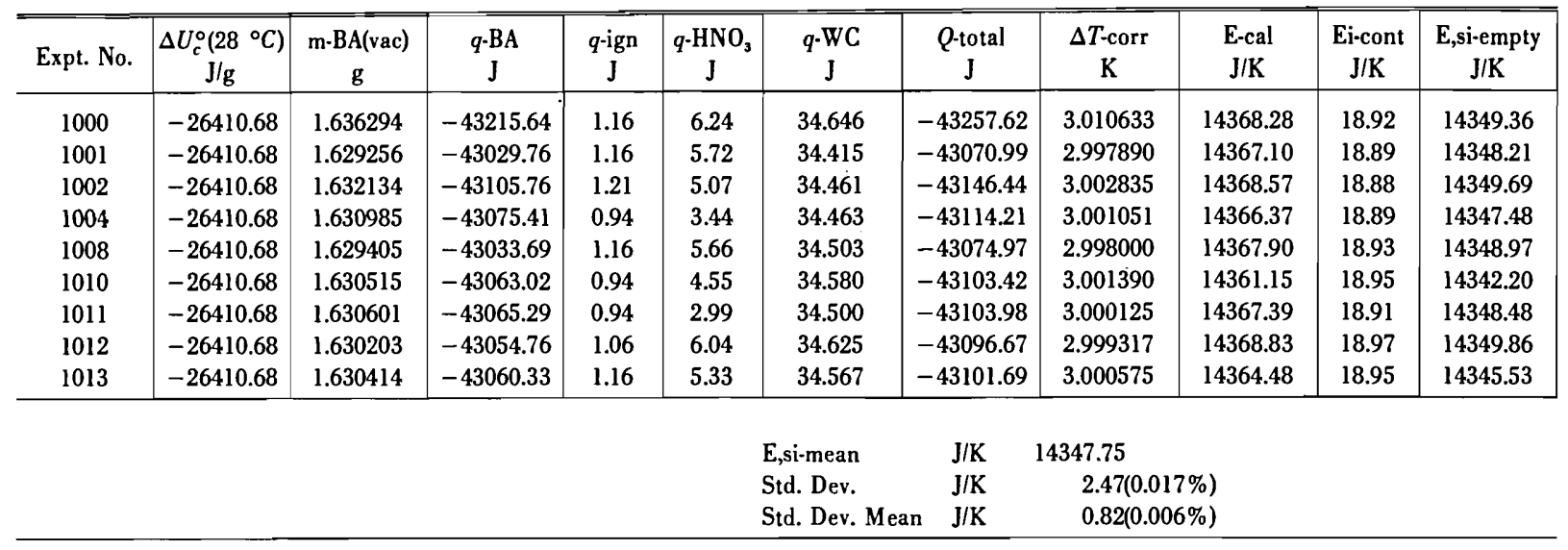

Ei-cont, the heat capacity of the initial bomb contents, including the sample, crucible, water, and oxygen, in J/K.

E,si-empty, the energy equivalent of the empty calorimeter at $28{ }^{\circ} \mathrm{C}$, in $\mathrm{J} / \mathrm{K}$.

$E$,si-mean, the mean value of the measured energy equivalent, in $\mathrm{J} / \mathrm{K}$.

Std. Dev., the standard deviation of a measurement, (sd), in $\mathrm{J} / \mathrm{K}$ (and the percent standard deviation, \%sd).

Std. Dev. Mean, the standard deviation of the mean, $(\mathrm{sdm})$ in $\mathrm{J} / \mathrm{K}$ (and the percent standard deviation of the mean, \% sdm).

The combustion data for Avicel are presented in table III. These are additional headings used in the table that were not described previously and are identified as follows:

$q$-wetting, a correction to the overall energy due to the combustion of the wetted sample, in J. When the sample is wetted, heat is evolved. During the burning process, that amount of water used in pre-wetting the sample is dried during the combustion. Therefore, the amount of heat generated in the combustion reaction is less than would be expected due to the amount of heat required to dry the sample. The number of joules due to the combustion of the compound initially is smaller and the amount of heat due to the wetting must be put back in to produce the correct enthalpy of combustion.

$q$-corr to $t_{f}$, A correction applied for the deviation of the actual final temperature from the selected standard final temperature (ussually $28^{\circ} \mathrm{C}$ ), in $\mathrm{J}$.

$Q$-cellulose, total energy delivered to the calorimeter after corrections for ignition energy, formation of nitric acid, sulfuric acid, heat of wetting and the like, in J.

$m$-cellulose, mass of the Avicel (cellulose) sample, in $\mathrm{g}$, reduced to mass in vacuum.

$\Delta U_{c}^{\circ}\left(28^{\circ} \mathrm{C}\right)$, the internal energy of combustion of the cellulose sample at constant volume in $\mathrm{J} / \mathrm{g}$. $\triangle n R T$, the correction term needed to change $\Delta U_{c}^{\circ}$ to $\Delta H_{c}^{\circ}$ at a given temperature.

$\Delta H_{c}^{\mathrm{g}}\left(28^{\circ} \mathrm{C}\right)$, the enthalpy of combustion of the sample in pure oxygen at the final temperature, in $\mathrm{kJ} / \mathrm{mole}$.

$\Delta C_{p} \Delta T$, a correction which includes the calculated change of heat capacity of the calorimeter system with temperature $\left(25-28{ }^{\circ} \mathrm{C}\right)$, in $\mathrm{kJ} / \mathrm{mole}$. The following values for $C_{p} / \mathrm{Jmol}^{-1}$ at $298 \mathrm{~K}$ were used: $\alpha$-cellulose $\mathrm{C}_{6} \mathrm{H}_{10} \mathrm{O}_{5}(\mathrm{c})$, 188.554 [16]: $\mathrm{O}_{2}(\mathrm{~g}), 29.355: \mathrm{CO}_{2}(\mathrm{~g}), 37.112: \mathrm{H}_{2} \mathrm{O}(\mathrm{liq}), 75.291$.

$\Delta H_{\mathrm{c}}\left(25^{\circ} \mathrm{C}\right)$, the enthalpy of combustion of the sample at the standard temperature, in $\mathrm{kJ} / \mathrm{mole}$.

A mean value of $-17340.76 \pm 3.44 \mathrm{~J} / \mathrm{g}(2 \mathrm{sdm})$ was obtained for the internal energy of combustion, $\Delta U_{c}^{\circ}$, of the Avicel sample at $28^{\circ} \mathrm{C}$, according to eq. (1).

$$
\mathrm{C}_{6} \mathrm{H}_{10} \mathrm{O}_{5}(\mathrm{c})+6 \mathrm{O}_{2}(\mathrm{~g}) \rightarrow 6 \mathrm{CO}_{2}(\mathrm{~g})+5 \mathrm{H}_{2} \mathrm{O}(\mathrm{liq})
$$

The formula weight of cellulose used in this study is $162.1439 \mathrm{~g} / \mathrm{mole}$.

The results of this study and the values derived from the results are summarized in table IV. The uncertainties assigned to $\Delta U_{c}^{\circ}$ and $\Delta H_{c}^{\circ}$ were obtained by combining (square root of the sum of the squares) $2 \mathrm{sdm}$ (in \%) for the calibration experiments, $2 \mathrm{sdm}$ (in \%) for the combustion experiments, 0.01 percent for the possible effect of organic impurities in the sample, 0.01 percent for the uncertainty in the certified value for benzoic acid and reasonable estimates of all other sources of error, 0.01 percent.

Our values are calculated at $30{ }^{\circ} \mathrm{C}$ for purposes of comparison with work that was carried out by Jessup and Prosen [3]. Their $\Delta U_{c}^{\circ}\left(30{ }^{\circ} \mathrm{C}\right)$ for wood pulp is $-17385.9 \pm 18.9$ $\mathrm{J} / \mathrm{g}(\mathrm{sdm})$ which is a mean of three experiments. Our results are $\Delta U_{c}\left(30{ }^{\circ} \mathrm{C}\right)=-17337.86 \pm 3.44 \mathrm{~J} / \mathrm{g}(2 \mathrm{sdm})$. Both of these values are calculated based upon the mass of sample burned. A 0.276 percent difference exists between the two 
TABLE III. Combustion Data on Cellulose

\begin{tabular}{|c|c|c|c|c|c|c|c|c|c|c|}
\hline Expt. No. & & 1014 & 1015 & 1016 & 1018 & 1020 & 1021 & 1023 & 1024 & 1032 \\
\hline$E$, si-empty & $J / K$ & 14347.75 & 14347.75 & 14347.75 & 14347.75 & 14347.75 & 14347.75 & 14347.75 & 14347.75 & 14347.75 \\
\hline Ei-cont & $\mathrm{J} / \mathrm{K}$ & 28.04 & 28.62 & 28.79 & 28.47 & 28.24 & 28.28 & 28.15 & 28.46 & 28.29 \\
\hline$E_{\text {-cal }}$ & $\mathrm{J} / \mathrm{K}$ & 14375.79 & 14376.37 & 14376.55 & 14376.23 & 14375.99 & 14376.03 & 14375.90 & 14376.22 & 14376.04 \\
\hline$\Delta T$-corr & $\mathbf{K}$ & 2.755973 & 2.894679 & 2.941978 & 2.858541 & 2.801024 & 2.811611 & 2.779214 & 2,851034 & 2.816332 \\
\hline$Q$-total & $\mathrm{J}$ & -39619.30 & -41614.99 & -42295.48 & -41095.04 & -40267.49 & -40419.82 & -39953.71 & -40987.08 & -40487.71 \\
\hline$q$-ign & J & 1.16 & 1.16 & 1.49 & 1.22 & 1.49 & 1.18 & 1.24 & 0.92 & 0.84 \\
\hline$q$-HNO & $J$ & -44.5308 & -45.3003 & -23.7486 & -45.0477 & -45.9112 & -44.7364 & -45.6938 & -43.9845 & -29.0646 \\
\hline$q$-wetting & $\mathrm{J}$ & -21.2809 & -22.3577 & -22.7384 & -22.0796 & -21.6333 & -21.7140 & -21.4625 & -22.0711 & -21.7420 \\
\hline$q \cdot \mathrm{WC}$ & $\mathrm{J}$ & 34.6815 & 36.8266 & 37.5677 & 36.2776 & 35.3811 & 35.5512 & 35.0807 & 36.2219 & 35.6218 \\
\hline$q$-corr to $\mathrm{t}$, & $\mathrm{J}$ & -2.0237 & -1.4655 & -1.2200 & -1.5837 & -1.7402 & -1.8014 & -1.9352 & -1.6774 & -1.7742 \\
\hline Qcellulose & $\mathrm{J}$ & -39562.23 & -41555.25 & -42256.64 & -41036.15 & -40208.08 & -40361.86 & -39895.09 & -40929.65 & -40445.70 \\
\hline$m$-cellulose & $g$ & 2.281250 & 2.396698 & 2.437510 & 2.366881 & 2.319141 & 2.327693 & 2.300729 & 2.360262 & 2.330697 \\
\hline$\Delta U_{c}^{\circ}\left(28{ }^{\circ} \mathrm{C}\right.$ & $\mathrm{C}) \mathrm{J} / \mathrm{g}$ & -17352.35 & -17338.66 & -17355.98 & -17337.65 & -17337.49 & -17339.86 & -17340.20 & -17341.15 & -17353.48 \\
\hline$\Delta n R T^{a}$ & $\mathrm{~kJ} / \mathrm{mol}$ & 0 & 0 & 0 & 0 & 0 & 0 & 0 & 0 & 0 \\
\hline$\Delta H_{c}^{\circ}\left(28{ }^{\circ} \mathrm{C}\right.$ & C) $\mathrm{kJ} / \mathrm{mol}$ & -2811.956 & -2811.358 & -2810.923 & -2811.194 & -2811.168 & -2811.553 & -2811.608 & -2811.762 & -2813.761 \\
\hline$\Delta C,(\Delta T)$ & $\mathrm{kJ} / \mathrm{mol}$ & -0.703 & -0.703 & -0.703 & -0.703 & -0.703 & -0.703 & -0.703 & -0.703 & -0.703 \\
\hline$\Delta H_{c}^{\circ}\left(25^{\circ} \mathrm{C}\right.$ & C) $\mathrm{kJ} / \mathrm{mol}$ & -2812.659 & -2812.061 & -2811.626 & -2811.897 & -2811.871 & -2812.256 & -2812.311 & -2812.465 & -2814.464 \\
\hline
\end{tabular}

'The values of atomic weights used in this work are:

$0=15.9994, \mathrm{C}=12.0112, \mathrm{H}=1.00797$

$\begin{array}{llr}\text { Mean, } \Delta H_{\mathrm{c}}^{\circ}\left(28{ }^{\circ} \mathrm{C}\right) & \mathrm{kJ} / \mathrm{mol} & -2811.698 \\ \text { Std. Dev. } & \mathrm{kJ} / \mathrm{mol} & 0.84(.030 \%) \\ \text { Std. Dev. Mean } & \mathrm{kJ} / \mathrm{mol} & 0.28(.010 \%)\end{array}$

TABLE IV. Data Summary with Estimated Uncertainty.

$\begin{array}{ll}\Delta U_{c}^{\circ}\left(28^{\circ} \mathrm{C}\right) & -17340.76 \pm 10.64 \mathrm{~J} / \mathrm{g} \\ \Delta H_{c}^{\circ}\left(28^{\circ} \mathrm{C}\right) & -2811.698 \pm 1.725 \mathrm{~kJ} / \mathrm{mol} \\ \Delta H_{c}^{\circ}\left(25^{\circ} \mathrm{C}\right) & -2812.401 \pm 1.725 \mathrm{~kJ} / \mathrm{mol}\end{array}$

values, but considering that Jessup and Prosen's sample was not well characterized and its purity uncertain, the values are in very good agreement. Our precision indicates that the Avicel can be burned very reproducibly.

\section{Summary and Conclusions}

A test substance with characteristics and properties similar to those of cellulose-based solid waste products is needed to calibrate calorimeters and combustors which will be routinely burning these materials to determine their calorific values precisely for use in commerce.

Microcrystalline cellulose is a good calibrant for this purpose because it is ashless, of high purity, homongeneous, inexpensive, and easy to pelletize. For hygroscopic cellulose materials a heat of wetting correction is neccessary. Extremely dry cellulose does not produce a complete burn in a combustion calorimeter. Our heat of wetting correction of $1.514 \mathrm{~kJ} / \mathrm{mol}$ was calculated based upon previous data in the literature. The enthalpy of combustion of microcrystalline cellulose, $\Delta H_{c}^{\circ}$ at $\left(25^{\circ} \mathrm{C}\right)$, and its estimated uncertainty, was determined to be $-2812.401 \pm 1.725 \mathrm{~kJ} / \mathrm{mol}$ based upon the sample mass. Microcrystalline cellulose appears to have good potential for serving as a test substance in the combustion calorimetry of cellulose-based solid waste products.

\section{References}

[1] Waddington, Guy. Physicochemical Standards for Thermochemistry, chap. 13 in Experimental Thermochemistry, Vol. 1. F.D. Rossini, ed. NY: Interscience Publishers, Inc.; 1956. 287-295.

[2] Prosen, Edward J.; Rossini, Frederick D. "Heats of Izomerization of the Five Hexanes." J. Res. Nat. Bur. Stand. (U.S.) 27: 289-310; September 1941.

[3] Jessup, Ralph S.; Prosen, Edward J.; "Heats of Combustion and Formation of Cellulose and Nitrocellulose." J. Res. Nat. Bur. Stand. (U.S.) 44: 387-393; April 1950.

[4] Coops, J.; Jessup, R.S.; van Nes, K. Calibration of Calorimeters for Reactions in a Bomb at Constant Volume, chapter 3 in Experimental Thermochemistry, Vol. 1. F.D. Rossini, ed. NY: Interscience Publishers, Inc.; 1956. 27-58.

[5] Wahba, M.; Nashed, S. The effect of hysteresis on the heat of wetting of partially saturated cellulose in water and its bearing on the physical structure of cellulose. Proceedings of the Egyptain Academy of Sciences. 8: 128-139; December 1952.

[6] Wahba, M.; Moisture relationships of cellulose. I. J. Physical \& Colloidal Chem. 52: 1197-1208; 1948.

[7] Wahba, M.; Moisture relationships of cellulose. II. J. Physical \& Colloidal Chem. 54: 1148-1160; 1950.

[8] Wahba, M; Aziz, K.; Moisture relations of cellulose, J. Textile Institute 50: T558-T568; 1959.

[9] Wahba, M.; Aziz, K.; Hysteresis and the heats of sorption of water on cotton cellulose below and above its second-order transition of about $25^{\circ} \mathrm{C}$. Chemica. Scripta. 7: 233-238; 1975.

[10] Argue, G.H.; Maas, 0.; Measurement of the heats of wetting of cellu. lose and wood pulp. Can. J. Chem. 12: 564-574; 1935. 
[11] Morrison, J.L.; Dzieciuch, M.A. The thermodynamic properties of the system cellulose-water vapor. Can. J. Chem. 37(9): 1379-1390; September 1959.

[12] Rees, Howard W. The heat of absorption of water by cellulose. Journal of the Textile Institute, Transactions. 39: T351-T367; November 1948.

[13] Sunner, S. and Mansson, M.; Combustion Calorimetry, Experimental
Chemical Thermodynamics, Volume 1, Pergamon Press; 1979.

[14] Rossini, F.D., Experimental Thermochemistry, Interscience Publishers, Inc., New York, N.Y. 1956.

[15] Washburn, E.W.; J. Res. Nat. Bur. Stand. (U.S.) 10: 525; 1933.

[16] Domalski, Eugene S.; Evans, William H.; Jobe, Thomas L. Jr., Thermodynamic Data for Waste Incineration. Nat. Bur. Stand. (U.S.) NBSIR 78-1479; August 1978. 158 p. 